\title{
A COUPLED MARINE ICE-STREAM - ICE-SHELF MODEL
}

\author{
By ISABELLE MUSZYNSKI and G.E. BIRCHFIELD
}

(Department of Geological Sciences, Northwestern University, Evanston, Illinois 60201, U.S.A.)

\begin{abstract}
Evidence as to the potential roles of marine ice flows in the dramatic climatological changes which have occurred from the late Pleistocene to the present is reviewed, indicating the need for careful modeling studies to evaluate several crucial hypotheses. A scale analysis of the flow of a marine ice stream coupled to a freely floating ice shelf is presented, in two dimensions and ignoring thermodynamic effects. With these limitations, the most important control of the dynamics of the ice stream is associated with first-order buoyancy effects related to the density contrast $\Delta \rho / \rho_{\mathrm{w}}$ between ice and sea-water. It is shown that longitudinal stretching, arising from large gradients in basal sliding velocity, dominates shearing deformation provided the aspect ratio $\omega^{2} \ll \Delta \rho / \rho_{\mathrm{w}}$. The buoyancy control is established through the necessity of having continuously varying longitudinal strain-rates in the neighborhood of the grounding line.

The scale analysis is the basis for derivation of a simplified model of a fast-flowing ice stream coupled to a freely floating ice shelf. The distance in the ice stream upstream from the grounding line over which the above dynamic regime extends is estimated and found to be relatively insensitive to the basal sliding velocity and to the rheological constant of ice. A further potentially important feed-back mechanism between ice stream and ice shelf is associated with buoyancy corrections to the longitudinal deviatoric stress field.
\end{abstract}

\section{INTRODUCTION}

In recent years, marine ice sheets have been a focus of attention for both the glaciological and paleoclimatological communities. While terrestral ice sheets rest on bedrock that is largely above contemporary sea-level, marine ice sheets are based on bedrock predominantly below contemporary sea-level. They are drained almost exclusively by fastflowing ice streams that discharge either directly into the ocean or into an attached ice shelf (Hughes, 1977). Ice shelves are in hydrostatic equilibrium with the ocean; the junction between the ice shelf and the ice stream, where the ice stream first becomes afloat, is the grounding line. It has been suggested (Hughes, 1973, 1975; Weertman, 1974) that marine ice sheets are inherently unstable and cannot exist at steady state. While a terrestrial ice sheet interacts directly only with the atmosphere, a marine ice sheet is also in contact with the ocean and responds to changes in oceanic temperatures, circulation, and sea-level. This is the reason for the significant difference in response times to climatic change, on the order of thousands of years for terrestrial ice sheets and of hundreds of years for marine ice sheets (Bentley, 1984). Marine ice sheets may thus well play an important role in shaping our near-future climatic environment and, especially in view of changes in the radiative properties of the atmosphere resulting from the burning of fossil fuels and industrial and thermal pollution, it is a question of some urgency to better our understanding of their behavior (National Research Council, 1985). On longer time scales, marine ice sheets may have been a critical component of the complex internal feed-back mechanisms active in the waxing and waning of the large Pleistocene ice sheets (Denton and Hughes, 1983). It is therefore important to clarify the dynamical differences between terrestrial and marine ice sheets in trying to explain the past.

Starting with Weertman's (1974) analysis of the stability of the junction of a marine ice sheet and an ice shelf and Thomas's (1977) zero-dimensional model for the groundingline retreat rate of a marine ice stream, several studies have addressed the question of marine ice-sheet and ice-stream dynamics. We have developed a much simplified but dynamically consistent model for a two-dimensional coupled marine ice-stream-ice-shelf system. Stresses and velocities are determined explicitly in terms of the ice thickness; icethickness profiles are obtained numerically. Numerical results will be published in a forthcoming paper (paper in preparation by I. Muszynski and G.E. Birchfield).

A discussion of potential roles of marine ice sheets in the climate changes of the late Pleistocene follows in the next section. A qualitative picture contrasting dominant physical processes in marine ice streams and terrestrial ice sheets is followed by presentation of the simplified model that explicitly incorporates dominant processes appropriate for marine ice streams (with details of derivation delegated to Appendix A). Discussion of the coupled ice-streamice-shelf model follows with conclusions.

\section{CLIMATOLOGICAL ROLE OF ICE SHEETS}

Large polar ice masses, whether terrestrial or marine, interact with the mean climatic state in a variety of ways. For the Earth as a whole, a balance exists on long timescales between the absorption of incoming shortwave solar radiation and the emission of longwave radiation back to space. The amount of solar energy absorbed depends on the planetary albedo. The planetary albedo is a function of the surface albedo of the Earth, the atmospheric concentrations of aerosols, and the characteristics of the cloud cover. The pioneering energy-balance modeling experiments of Budyko (1969) and Sellers (1969) raised the possibility of an icecovered Earth catastrophe due to the dependence of the surface albedo on temperature and thus on ice-sheet extent, and spurred intensive investigation of global climate sensitivity to this albedo-temperature feed-back mechanism. Extensive discussions of the ice-albedo feed-back and of climate sensitivity can be found in Schneider and Dickinson (1974), North and others (1981), and Dickinson (1985). Another important feed-back mechanism involves the dependence of the longwave flux on the surface temperature of the ice sheet; the temperature itself is a complicated function of the lapse rate, the surface elevation of the ice sheet, the accumulation rate at the surface of the ice sheet, and the rate of isostatic adjustment of the bedrock under the ice load (Oerlemans, 1980; Bowman, 1982; Pollard, 1982; Birchfield and Grumbine, 1985; Muszynski and Birchfield, 1985). The zonal radiation budget is unbalanced, with a net excess of energy at low latitudes and a net deficit at high latitudes. The resulting meridional thermal gradient is the main driving force of the atmospheric and oceanic circulations. A high-latitude cooling due to growth of the ice cover will intensify the Equator to pole temperature gradient and will be counteracted by an increased poleward flux of latent and sensible heat (Schneider and Dickinson, 1974; Saltzman and others, 1982). A complex but potentially 
very important feed-back concerns the effects of ice-sheet topography and extent on the zonal atmospheric circulation. Disturbances in the planetary wave structure and winds resulting from a temperature-inversion layer over the ice sheet would both result in the Equatorward advection of cold air (Schwerdtfeger, 1970; Hartmann, 1984). Not only would these cold air masses enhance the albedo feed-back by helping preserve winter snow cover on land but they would also increase the land-ocean temperature contrast and thereby influence sea-ice extent, sea-surface temperature, and cyclone tracks and precipitation patterns (Ruddiman and McIntyre, 1981[a]; Hartmann, 1984; Manabe and Broccoli, 1985[b]). Other feed-back mechanisms are related to the temperature dependence of ice rheology (Glen, 1955): as its temperature rises, ice softens and strain-rates increase. Down-draw of the ice-sheet interior results (Hughes, 1981) and the lapse-rate feed-back causes a further rise in temperature at the surface of the ice sheet. Higher air temperatures will also lead to higher surface melt rates. This melt water percolates into crevasses and either refreezes inside the ice column or reaches the bed. The latent heat released upon refreezing of the melt water will soften the ice and compound the effect of the temperature increase (Hughes, 1986). An increase in the amount of basal water will result in a higher sliding velocity at the bed through increased bed separation and basal water pressure (e.g. Bindschadler, 1983; Weertman and Birchfield, 1983).

Marine ice streams and ice shelves are involved in an additional series of feed-back mechanisms that affect the stability of the grounding line and may either enhance or reduce the effects of the above feed-back loops. The rate of advance or retreat of the grounding line depends on the local surface and bedrock slopes, the local mass balance and the rate of sea-level change (Thomas and Bentley, 1978) Through non-linear positive feed-back mechanisms, a small perturbation in one of these parameters may result in a run-away process in which the initial small displacement of the grounding line is amplified until the marine ice sheet completely collapses or extends to the edge of the continental shelf (Thomas, 1979[b]). If the bedrock depth increases inland from the grounding line, a rise in sea-level, for example, may lift a part of the ice stream free of its bed and effectively float the marginal zone of the ice stream, causing the grounding line to retreat inland to a region of greater ice thicknesses. Because of the strong dependence of the creep rate at the grounding line on ice thickness (Weertman, 1957), ice discharge at the grounding line will increase, resulting in down-draw of the ice-sheet surface in the drainage basin of the ice stream, a decrease in basal shear stress, and thus an acceleration of the collapse of the marine ice sheet (Hughes, 1975, 1981). These are all positive feed-back mechanisms that will amplify the initial perturbation. In the absence of an ice shelf, complete collapse of the marine ice sheet may result unless a bedrock sill anchors the grounding line (Crabtree and Doake, 1982; Thomas, 1984; Doake, 1985) by slowing down ice discharge and causing up-stream thickening of the ice.

The two major mechanisms for stabilizing the grounding line, however, involve the interaction of an ice stream with an ice shelf (e.g. Thomas, 1979[a], [b], 1984; Bentley, 1984). If an ice stream has to expend work to push its ice into and through an ice shelf, there will be less gravitational potential energy available for conversion into frictional energy dissipation at the glacier base and the discharge rate at the grounding line will decrease. A distinction is traditionally made between unbounded or freely floating ice shelves and bounded ice shelves which flow in a channel or embayment. The retarding force exerted by these solid boundaries on the ice-shelf flow leads to a decrease in ice-shelf thinning rates and thereby has a damming effect on ice-stream discharge into the ice shelf. Grounding-line thicknesses are extremely sensitive to the dynamic state of the ice shelves into which the ice streams drain. While the grounding-line thickness of an ice stream attached to a freely floating ice shelf would be approximately $400 \mathrm{~m}$ (Weertman, 1974), thicknesses of $1000 \mathrm{~m}$ are not uncommon. The excess compressive stress above that provided by buoyancy alone at an ice-stream grounding line has been termed back-pressure by Thomas (1973). The back-pressure depends on the geometry of the embayment (Sanderson, 1979) and on the length of the ice shelf, and thus on the relative rates of grounding-line movement and iceberg calving at the front of the ice shelf (Hughes, 1982; Fastook, 1984). A climatic warming, resulting in larger amounts of melt water at the surface of the ice shelf and in a change in calving mechanism from intermittent production of large tabular icebergs to "explosive" production of small icebergs (Thomas, 1984), may thus decrease the ice-shelf back-pressure and destabilize the ice stream. Shallow bedrock shoals, on which the ice shelf runs aground, provide another source of back-pressure by impeding the ice-shelf flow. Ice shelves are very vulnerable to increased bottom melting rates which would result in two competing effects (Thomas, 1985; MacAyeal, unpublished): increased thinning rates, with the possibility of ice-shelf ungrounding at the deeper pinning points, would increase the ice-stream discharge rate at the grounding line, while the selective removal of the warmest and thus softest ice from the ice column would decrease the depth-averaged ice temperature and thus stiffen the remaining ice, thereby decreasing ice-shelf strain-rates and stabilizing the grounding line. This second effect would be enhanced by the increased advection of cold ice-stream ice. It is not yet clear, however, whether a climatic warming would significantly affect the temperature of the waters circulating in the sub-ice-shelf cavities (MacAyeal, 1984; Jacobs, 1985). Ice-shelf pinning or unpinning may also occur as the result of isostatic rebound (Thomas, 1976).

The scale of climatic variability associated with a particular climatic component depends upon its response time to external forcings and to changes in the internal configuration of other climatic sub-systems (Saltzman, 1983). Because the time needed for an ice sheet to adjust its volume to a change in external boundary conditions is very long, terrestrial ice sheets contribute mainly to long-term climatic trends, although some short-term climatic variability may be associated with the fast response time of surface conditions associated with a snow and ice cover, such as the amount of summer melt water. Bentley (1984) estimated that the potential instability of the grounding line of a marine ice sheet leads to a decrease in its response time by about an order of magnitude, from thousands to hundreds of years. The reaction of the West Antarctic ice sheet, which is today's only truly marine ice sheet, to a $\mathrm{CO}_{2}$-induced climatic warming therefore is the cause of great concern among the glaciological and climatological communities; unfortunately, there is as yet no clear consensus as to the likelihood of its collapse or the time-scale over which such a collapse would take place (see, for example, Mercer, 1978; National Research Council, 1985).

Climatic variability on time-scales of $10-400 \mathrm{ka}$ is thought to be the consequence of astronomical forcing (e.g. Saltzman, 1983). The astronomical or Milankovitch theory postulates that the small insolation fluctuations due to the quasi-periodic changes in the obliquity of the Earth's axis and in the eccentricity and longitude of perihelion of its orbit can be amplified sufficiently by internal feed-back mechanisms to cause the Pleistocene succession of glacial and interglacial episodes observed in the paleoclimatic record (e.g. Imbrie and Imbrie, 1979; Imbrie, 1985). The main spectral power of orbital variations occurs near periods of 413,100 , and $54 \mathrm{ka}$ for eccentricity; $41 \mathrm{ka}$ for obliquity; and 23 and $19 \mathrm{ka}$ for precession. The spectrum of the Earth's response, as measured in proxy paleoclimatic records, contains main peaks at periods of $100,41,23$, and $19 \mathrm{ka}$ and is clearly correlated with the astronomical forcing for the Northern Hemisphere. As it stands today, the Milankovitch theory has two puzzling features. The first of these concerns the response of the climate system at the eccentricity-related $100 \mathrm{ka}$ period, which is much stronger than the corresponding orbital forcing. This suggests that the spectral response at $100 \mathrm{ka}$ represents a non-linear response of the climate system. As we have seen, ice sheets participate in a very rich spectrum of feed-back loops; they obey a non-linear flow law, have a very slow volume response time, and interact with the lithosphere on long time-scales. They are thus a prime candidate for explanation of the $100 \mathrm{ka}$ paradox. A series of studies has explored this possibility (e.g. Birchfield and others, 1981; Oerlemans, 1982[a]; Le Treut and Ghil, 1983; Peltier and 
Hyde, 1984; Pollard, 1984; Birchfield and Grumbine, 1985). Although they clearly show the correlation between ice-volume changes and Northern Hemisphere insolation fluctuations, and do produce simulated ice-volume curves that resemble those deduced from the oxygen stable-isotope record, their spectral power at $100 \mathrm{ka}$ is still somewhat less than is seen in the proxy record. A common characteristic of these modeling studies is that they consider the interaction between a single, Northern Hemisphere continental ice sheet and the insolation forcing. They are thus inadequate to explore the role of Southern Hemisphere ice sheets, in particular the Antarctic ice sheet, in the Pleistocene ice ages.

The second Milankovitch paradox concerns interhemispheric interactions. While the insolation anomalies associated with the obliquity are symmetric between the hemispheres, those associated with the precession of perihelion are anti-symmetric. Global circulation-model studies indicate that, perhaps because it is largely oceanic, the Southern Hemisphere is hardly affected by the presence of large Northern Hemisphere ice sheets (Manabe and Broccoli, 1985[b]). Detailed studies of ice-extent markers, however, indicate that mountain-glacier fluctuations in both hemispheres were nearly synchronous (Mercer, 1984), and foraminiferal evidence suggests that sea-surface temperature changes in the sub-Antarctic slightly pre-date the ice-volume changes associated with the demise of the large Northern Hemisphere ice sheets (Hays and others, 1976). Moreover, glacial terminations are slightly more abrupt in the Southern than in the Northern Hemisphere (Broecker, 1984). How, then, are deglaciations driven? Part of the answer probably lies in the existence, in the climate system, of one or more fast mechanisms able to transform Northern Hemisphere insolation fluctuations into world-wide temperature changes. In the last few years, attention has been increasingly focused on the role of the deep ocean, more particularly the cross-equatorial heat flux and the effect of high-latitude deep convection on bottom-water production and atmospheric $\mathrm{CO}_{2}$ concentration (Boyle and Keigwin, 1982; Broecker, 1984; Broecker and Takahashi, 1984; Ennever and McElroy, 1985; Manabe and Broccoli, 1985[a]; Toggweiler and Sarmiento, 1985; Wenk and Siegenthaler, 1985). Further important clues were furnished by Ruddiman and McIntyre (1981[b]), who found evidence that the last glacial Northern Hemisphere ice sheets may have substantially decreased in volume before shrinking in area, thereby raising the possibility that down-draw effects in the drainage basins of marine components (Stuiver and others, 1981) played a critical role, and by Denton and Hughes (1983), who asserted that, at the last glacial maximum, a critical part of the large Northern Hemisphere ice sheets may have become marine because of isostatic adjustment under the ice load. They proposed that summer melting of Northern Hemisphere terrestrial ice-sheet margins, caused by a favorable orbital configuration, leads to a change in eustatic sea-level that, in turn, destabilizes all marine ice-sheet components. Increased interior down-draw and grounding-line retreat, migration of ice divides between adjacent terrestrial and marine drainage basins, and albedo and other positive feed-back mechanisms all amplify the initial marginal melting and ultimately lead to total collapse of the ice sheets. To summarize, then, there is considerable evidence that marine ice sheets may be critical cryospheric components on short, as well as long, time-scales of climatic variability.

\section{A MARINE ICE-STREAM MODEL}

\section{Marine ice-stream physics, a qualitative model}

The flow regime of an ice mass is largely determined by conditions at the ice-bedrock interface. A terrestrial ice sheet which is frozen to its bed is subject to two forces: gravity and the drag force exerted by the bedrock on the ice; the resulting normal stress field is therefore essentially isotropic, that is, the normal deviatoric stresses are small compared with the shear stress. The longitudinal strain-rate or stretching may then be neglected compared with the shear strain-rate and movement will be by shearing only. Equating the normal stresses to the glaciostatic pressure, it is then possible to obtain the shear stress by balancing the gravitationally induced driving stress and the basal shear stress acting along the ice-bedrock interface. The velocity, in turn, follows from the rheology by integration of the shear strain-rate.

If the ice is not frozen to the bed, but basal conditions are such that the sliding velocity and its downstream gradient are small, the response is the same except for the addition of a bottom-sliding component to the velocity. As the sliding velocity increases (due to pressure-melting of the basal ice, for example), its down-stream gradient may become comparable in magnitude to the shear strain-rate and stretching may no longer be negligible compared with shearing. In a surging glacier, for example, the sliding velocity is so large that stretching becomes the dominant deformation process (e.g. McMeeking and Johnson, 1986 and references therein). Corrections to the frozen-bed solution under these circumstances have been obtained by asymptotic methods (Hutter, 1981; Shoemaker and Morland, 1984; McMeeking and Johnson, 1985).

For a marine ice stream with attached freely floating ice shelf, strain heating, inland seepage of sea-water, and subglacial buoyancy effects associated with the marine character of the ice stream all contribute to establishing a strong gradient in basal sliding velocity between the head of the ice stream and its grounding line. This suggests that the dominant deformation process in the marine ice stream is longitudinal stretching. We shall assume that the predominance of stretching over shearing is a distinguishing property of marine ice streams. Since, in the floating ice shelf, shear stresses must be small, the dominant deformation rate must also be a stretching. Weertman (1957) and Thomas (1973) have demonstrated that this stretching is induced by the deviatoric normal stress which itself is ultimately due to the density difference between the ice shelf and sea-water. It is obvious that in the region of the grounding line the longitudinal strain-rate produced by these two distinct mechanisms varies continuously from the ice stream to the ice shelf. It is through this coupling that the basal-sliding control of the ice stream affects the flow of the ice shelf and, vice versa, that changes in the dynamic state of the ice shelf, for example through grounding or ungrounding, affect the dynamics of the ice stream. The up-stream limit of this domain of influence of the ice shelf on the ice stream is estimated in the discussion. A further feed-back mechanism that may be important in this coupling is also discussed there.

\section{Marine ice-stream physics, a scaled model}

As the dynamics of a laterally unbounded ice shelf are well understood (Weertman, 1957; Thomas, 1973), we limit our discussion here primarily to the marine ice-stream domain. We first present the full, unsimplified system of equations and boundary conditions; this is followed by a simple, but fundamental scaling analysis which substantiates the discussion in the previous section and provides the basis for our coupled model. The simplified ice-stream model is then presented, with details relegated to Appendix A. To demonstrate overall dynamical consistency of the coupled model, a scale analysis of the freely floating ice shelf is presented in Appendix B.

Consider a Cartesian coordinate system, with $x$ horizontal along the longitudinal axis and $y$ along the vertical axis, as illustrated in Figure 1. The $y$-axis denotes the up-stream limit of the ice-stream flow regime and is assumed fixed in space and time. The ice shelf extends from the grounding line, at $x=x^{*}$, to $x=L$. For simplicity, we assume that the ice stream rests on a rigid bed and that the bedrock profile is linear with slope $\phi>0$. The bedrock depth is zero at $x=0$. In both ice sheet and ice shelf, $h^{\prime}$ is the ice-surface elevation and $H$ the total ice thickness. In the ice sheet, $h$ is the bedrock depth, $h=\phi x$, while in the ice shelf it is the depth to the bottom ice surface. Thus, $H=h^{\prime}+h$. The surface slope of the ice is $\partial h^{\prime} / \partial x=-\alpha(\alpha>0)$, the bottom slope $\partial h / \partial x=\phi$. If $\rho_{\mathrm{w}}$ is the density of sea-water, $\rho_{i}$ the density of ice (both assumed constant), and $\Delta \rho=\rho_{\mathrm{w}}-\rho_{\mathrm{i}}$, hydrostatic equilibrium in the ice shelf requires that

$$
\frac{\partial h}{\partial x}=-\frac{\rho_{i}}{\Delta \rho} \alpha
$$




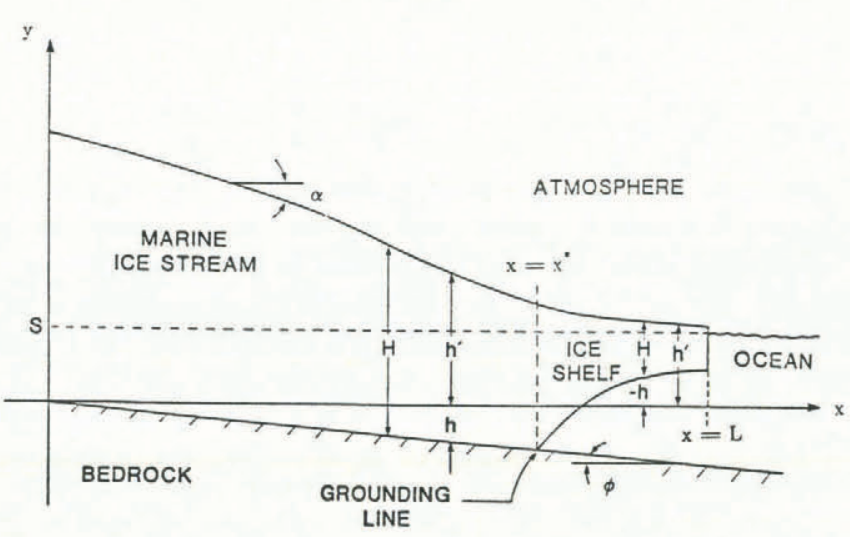

Fig. 1. Model geometry. The surface slope is $\alpha$, the bedrock slope $\phi$. The total ice thickness is $H$ and the surface elevation $h^{\prime}$. In the ice stream, $h=\phi x$, in the ice shelf,

$$
h=\frac{\rho_{\mathrm{i}}}{\rho_{\mathrm{w}}} H-S
$$

where $S$ is sea-level. The grounding line is at $x=x^{*}$, the ice-shelf front at $x=L$.

The bottom ice surface is thus known everywhere. The values of $h^{\prime}, h$, and $H$ at the grounding line are $h^{*}, h^{*}$, and $H^{*}$, and $S$ is sea-level.

Basic equations. We denote normal stresses by $\sigma_{i i}$, shear stresses by $\sigma_{i j}(i \neq j)$, and strain-rates by $\dot{\epsilon}_{i j}$; the longitudinal velocity is $u$ and the vertical velocity $v$. The dynamic and kinematic state of both an ice sheet and an ice shelf are described by the set of equations

$$
\begin{gathered}
\frac{\partial H}{\partial t}+\frac{\partial}{\partial x}(H u)=a-b, \\
\frac{\partial \sigma_{x x}}{\partial x}+\frac{\partial \sigma_{x y}}{\partial y}=0, \\
\frac{\partial \sigma_{x y}}{\partial x}+\frac{\partial \sigma_{y y}}{\partial y}=\rho_{\mathrm{i}} g, \\
\sigma_{x x}^{\prime}=\frac{1}{2}\left(\sigma_{x x}-\sigma_{y y}\right), \\
\sigma_{y y}^{\prime}=-\frac{1}{2}\left(\sigma_{x x}-\sigma_{y y}\right), \\
\tau^{2}\left(\sigma_{x x}^{\prime}{ }^{2}+\sigma_{y y^{\prime}}{ }^{2}\right)+\sigma_{x y}{ }^{2}, \\
\dot{\epsilon}_{x x}=\frac{\partial u}{\partial x}=A \tau^{2} \sigma_{x x}^{\prime}, \\
\dot{\epsilon}_{x y}=\frac{\partial v}{\partial y}=A \tau^{2} \sigma_{y y}^{\prime}, \\
\frac{1}{2}\left(\frac{\partial v}{\partial x}+\frac{\partial u}{\partial y}\right)=A \tau^{2} \sigma_{x y}
\end{gathered}
$$

with, for the marine ice stream, boundary conditions at $y=h^{\prime}$ :

$$
\begin{gathered}
\sigma_{x x} \sin \alpha+\sigma_{x y} \cos \alpha=0, \\
\sigma_{x y} \sin \alpha+\sigma_{y y} \cos \alpha=0, \\
\nu=\frac{\partial h^{\prime}}{\partial t}+u \frac{\partial h^{\prime}}{\partial x}-a,
\end{gathered}
$$

at $y=-h$ :

$$
-u \sin \phi-v \cos \phi=0,
$$

$u \cos \phi-v \sin \phi=F^{\prime}\left(\sigma_{x x}^{\prime} \sin 2 \phi+\sigma_{x y} \cos 2 \phi\right)^{m}$,

at $x=0$ :

$$
\begin{gathered}
H=H_{00}, \\
M=M_{00}, \\
\sigma_{x x}=\Sigma_{00},
\end{gathered}
$$

at $x=x^{*}$ :

$$
\begin{aligned}
\frac{\Delta \rho}{\rho_{\mathrm{w}}} H^{*} & =h^{\prime *}-S, \\
\sigma_{x x} & =\Sigma^{*}
\end{aligned}
$$

and, for the ice shelf

at $y=h^{\prime}$ :

$$
\begin{gathered}
\sigma_{x x} \sin \alpha+\sigma_{x y} \cos \alpha=0 \\
\sigma_{x y} \sin \alpha+\sigma_{y y} \cos \alpha=0 \\
v=\frac{\partial h^{\prime}}{\partial t}+u \frac{\partial h^{\prime}}{\partial x}-a
\end{gathered}
$$

at $y=-h$ :

$$
\begin{gathered}
\sigma_{x x} \sin \left[\frac{\Delta \rho}{\rho_{\mathrm{i}}} \alpha\right)-\sigma_{x y} \cos \left(\frac{\Delta \rho}{\rho_{\mathrm{i}}} \alpha\right)=-\rho_{\mathrm{w}} g h \sin \left[\frac{\Delta \rho}{\rho_{\mathrm{i}}} \alpha\right), \\
\sigma_{x y} \sin \left[\frac{\Delta \rho}{\rho_{\mathrm{i}}} \alpha\right)-\sigma_{y y} \cos \left(\frac{\Delta \rho}{\rho_{\mathrm{i}}} \alpha\right)=\rho_{\mathrm{w}} g h \cos \left[\frac{\Delta \rho}{\rho_{\mathrm{i}}} \alpha\right), \\
v=-\frac{\partial h}{\partial t}-u \frac{\partial h}{\partial x}+b,
\end{gathered}
$$

at $x=x^{*}$ :

$$
M=M^{*},
$$

at $x=L$,

$$
\int_{-h}^{h^{\prime}} \sigma_{x x} \mathrm{~d} y=\rho_{\mathrm{w}} g \int_{-h}^{0} y \mathrm{~d} y .
$$

Equation (1) is a vertically integrated statement of mass continuity for an incompressible material; $a-b$ is the net accumulation rate, equal to net surface accumulation minus bottom melting (in meters of ice equivalent/year). Equations (2) are stress equilibrium equations, with $g$ the vertical acceleration due to gravity. Equations (3) define the deviatoric stresses as being deviations from isotropy in the normal stress field, while Equation (4) defines the effective stress in terms of the deviatoric and shear stresses. Equations (5) constitute a statement of ice rheology and relate the stress and strain-rate fields. We have adopted a non-linear power-law rheology with exponent equal to three; the flow-law parameter $A$ is assumed constant. Equations $(6.1-2), \quad(10.1-2)$, and $(11.1-2)$ are stress-continuity conditions at the ice-air and ice-water interfaces (atmospheric pressure is assumed to be zero); Equations (6.3), (10.3), and (11.3) are kinematic conditions describing 
the location of the free surfaces. Equation (7.1) states that there is no penetration of ice into the bedrock, and Equation (7.2) is the conventional sliding law relating basal velocity and basal shear stress. $F^{\prime}$ is an empirical function of $(x, t)$, and $m$ a constant exponent, both discussed below. The boundary conditions at the origin (Equations (8)) and at the grounding line (Equations (9)) state that the ice thickness and the normal component of the stress vector are continuous at the junctions of the ice stream with the ice sheet at $x=0$, and with the ice shelf at $x=x^{*}$. Because the ice shelf is afloat everywhere, boundary condition (9.1) is also a flotation condition on the ice stream at the grounding line. Equation (12) expresses that the mass flux is continuous across the ice-stream-ice-shelf transition, and Equation (13) is an integrated stress continuity condition at the ice-shelf front.

$$
\text { For small } \alpha \text { and } \phi, \sin (\alpha, \phi) \approx \tan (\alpha, \phi) \approx \frac{\partial}{\partial x}\left(-h^{\prime}, h\right) \text {, }
$$
$\cos (\alpha, \phi) \approx 1$ and $\tan 2 \phi \approx 2 \tan \phi$. Boundary conditions (6) and (7) can therefore be rewritten more simply as

$$
\begin{array}{r}
-\sigma_{x x} \frac{\partial h^{\prime}}{\partial x}+\sigma_{x y}=0, \\
-\sigma_{x y} \frac{\partial h^{\prime}}{\partial x}+\sigma_{y y}=0, \\
u=F\left[2 \sigma_{x x}^{\prime} \frac{\partial h}{\partial x}+\sigma_{x y}\right]^{m}
\end{array}
$$

where $F=F^{\prime} \cos \phi \cos ^{m} 2 \phi$ and Equation (7.1) has been used to eliminate the vertical velocity $v$ from Equation (7.2).

Fundamental scale analysis. The traditional way to reduce the above equations in the case of a terrestrial ice sheet is to neglect the normal strain-rate equations (Equations $(5.1-2))$ and to retain only the shear strain-rate equation (Equation (5.3)). As pointed out above, this is not appropriate for a marine ice stream, as it implies isotropy of the normal stress field and dominance of shearing over stretching. We first note that the down-stream aspect ratio, i.e. the ratio of ice thickness, $H_{\mathrm{c}}$, to length, $L_{\mathrm{c}}$, denoted by $\omega^{2}$, of most large ice bodies is small, $\omega^{2} \approx 10^{-2}-10^{-3}$ Because of the dominance of gravity in the vertical, typical normal stresses in such bodies are $\sigma_{\mathrm{c}} \approx \rho_{\mathrm{j}} g H_{\mathrm{c}}$. Furthermore, as seen from Equation (2.1), the ratio of shear stress to normal stress must be of the order of the aspect ratio $\omega^{2}$. For the rapidly flowing ice stream in the neighborhood of the grounding line, we assert that the normal deviatoric stress must be larger than the shear stress. Suppose that this was not true, and that instead they were of the same order of magnitude $\omega^{2} \sigma_{\mathrm{c}}$. Estimating the longitudinal strain-rate as the ratio of a typical basal sliding velocity $U_{\mathrm{c}}$, to the length of the ice stream $L_{\mathrm{c}}$, by equation (5.1) we must have

$$
\frac{U_{\mathrm{c}}}{A_{\mathrm{c}} L_{\mathrm{c}} \sigma_{\mathrm{c}}{ }^{3}} \approx \omega^{6} \text {. }
$$

But for typical values $U_{\mathrm{c}} \approx 200 \mathrm{~m} \mathrm{a}^{-1}, L_{\mathrm{c}} \approx 100 \mathrm{~km}, A_{\mathrm{c}} \approx$ $1 \times 10^{-17} \mathrm{a}^{-1} \mathrm{~Pa}^{-3}$, and $\sigma_{\mathrm{c}} \approx 2.5 \times 10^{6} \mathrm{~Pa}$,

$$
\frac{U_{\mathrm{c}}}{A_{\mathrm{c}} L_{\mathrm{c}} \sigma_{\mathrm{c}}^{3}} \approx 1 \times 10^{-5} \gg \omega^{6} \text {. }
$$

Provided

$$
\omega^{2} \ll\left(\frac{U_{\mathrm{c}}}{A_{\mathrm{c}} L_{\mathrm{c}} \sigma_{\mathrm{c}}^{3}}\right)^{1 / 3},
$$

the basal sliding velocity clearly dictates large deviatoric stresses, of order

$$
\left[\frac{U_{\mathrm{c}}}{A_{\mathrm{c}} L_{\mathrm{c}}}\right]^{1 / 3} \text {, in the ice stream. }
$$

In the freely floating ice shelf, the deviatoric stress can be shown to be of order

$\frac{\Delta \rho}{\rho_{\mathrm{w}}} \sigma_{\mathrm{c}}$; as long as $\omega^{2} \ll \frac{\Delta \rho}{\rho_{\mathrm{w}}} \approx 10^{-1}$, the longitudinal deviatoric stress therefore dominates the shear stress and the longitudinal strain-rate in the ice shelf is of order

$$
\dot{\epsilon}_{\mathrm{c}} \approx A_{\mathrm{c}}\left[\frac{\Delta \rho}{\rho_{\mathrm{w}}} \sigma_{\mathrm{c}}\right]^{3} \text {. }
$$

Strain-rate continuity in the neighborhood of the grounding line then requires

$$
\frac{U_{\mathrm{c}}}{L_{\mathrm{c}}} \approx A_{\mathrm{c}}\left[\frac{\Delta \rho}{\rho_{\mathrm{w}}} \sigma_{\mathrm{c}}\right]^{3} .
$$

The basal sliding velocity of the ice stream and the dynamics of the ice shelf are thus coupled through the relationship

$$
U_{\mathrm{c}} \approx A_{\mathrm{c}} L_{\mathrm{c}}\left[\frac{\Delta \rho}{\rho_{\mathrm{w}}} \sigma_{\mathrm{c}}\right]^{3} \text { provided } \omega^{2} \ll \frac{\Delta \rho}{\rho_{\mathrm{w}}} .
$$

Finally, with this coupling constraint on $U_{\mathrm{c}}$, the ratio of shear stress to deviatoric stress in the ice stream becomes

$$
\left|\frac{\sigma_{x y}}{\sigma_{x x}^{\prime}}\right| \approx \omega^{2}\left[\frac{\Delta \rho}{\rho_{w}}\right]^{-1},
$$

so that the condition for dominance of stretching over shearing in the ice stream reduces to the same condition as in the ice shelf, $\omega^{2} \ll \frac{\Delta \rho}{\rho_{w}}$.

Marine ice-stream model. The above scale analysis, as applied in Appendix A, asserts that, for a fast-flowing marine ice stream, the original system of Equations (1) $-(5)$ can be replaced by the following, much simpler system, together with boundary conditions $\left(6^{\prime}\right),\left(7^{\prime}\right),(8)$, and $(9)$.

$$
\begin{gathered}
\frac{\partial H}{\partial t}+\frac{\partial}{\partial x}(H u)=a-b, \\
\frac{\partial \sigma_{x x}}{\partial x}+\frac{\partial \sigma_{x y}}{\partial y}=0, \\
\sigma_{y y}=-\rho_{\mathrm{i}} g\left(h^{\prime}-y\right), \\
\frac{\partial u}{\partial x}=\frac{A}{8}\left(\sigma_{x x}-\sigma_{y y}\right)^{3}, \\
\frac{\partial u}{\partial y}=0 .
\end{gathered}
$$

This sytem is integrated, using Equations $\left(6^{\prime}\right)$ and $\left(7^{\prime}\right)$, to give the final form for the marine ice-stream model:

$$
\begin{gathered}
\frac{\partial H}{\partial t}+\frac{\partial}{\partial x}(H u)=a-b \\
\sigma_{x x}^{\prime}=\left(\rho_{\mathrm{i}} g\right)^{m / 3} A^{-1 / 3}\left[\frac{\partial}{\partial x} F\left[-H \frac{\partial h^{\prime}}{\partial x}\right]^{m}\right]^{1 / 3},
\end{gathered}
$$




$$
\sigma_{x x}=-\rho_{\mathrm{i}} g\left(h^{\prime}-y\right)+2 \sigma_{x x}^{\prime},
$$

$$
\sigma_{x y}=-\rho_{\mathrm{i}} g\left(h^{\prime}-y\right) \frac{\partial h^{\prime}}{\partial x}+2 \frac{\partial}{\partial x}\left[\left(h^{\prime}-y\right) \sigma_{x x}^{\prime}\right]
$$

$$
u=\left[-\rho_{\mathrm{i}} g H \frac{\partial h^{\prime}}{\partial x}\right]^{m-1} F\left[-\rho_{\mathrm{i}} g H \frac{\partial h^{\prime}}{\partial x}+2 m \frac{\partial}{\partial x}\left(H \sigma_{x x}^{\prime}\right)\right]
$$

with boundary conditions (8) and (9) unchanged by the scale analysis.

The vertical normal stress in an ice shelf, whether bounded or not, is equal to the glacial overburden (Weertman, 1957; Thomas, 1973; Equation (B28)) and thus has the same functional expression as the vertical normal stress in the marine ice stream (Equation (15.2)). Equation (3.1) then shows that, at the grounding line, the continuity condition on the normal stress (Equation (9.2)) can be replaced by a continuity condition on the deviatoric stress. In a freely floating ice shelf, the deviatoric stress is

$$
\sigma_{x x}^{\prime}=\frac{1}{4} \rho_{\mathrm{i}} g \frac{\Delta \rho}{\rho_{\mathrm{w}}} H
$$

(Weertman, 1957; Thomas, 1973; Equation (B30)). If the ice shelf is grounded, however, this is no longer true. To allow for this case, we state boundary condition (9.2) simply as

$$
\sigma_{x x}^{\prime}=\Sigma^{\prime *}
$$

where $\Sigma^{\prime *}$ is a function of the dynamic state of the ice shelf.

\section{DISCUSSION AND CONCLUSIONS}

We have shown that the most important control of the dynamics of a fast-moving ice stream coupled to a freely floating ice shelf is associated with first-order buoyancy effects, that is, longitudinal stretching dominates shearing deformation in both the ice shelf and the ice stream provided the aspect ratio $\omega^{2} \ll \Delta \rho / \rho_{\mathrm{w}}$. This constraint is the basis for our simplified ice-stream model consisting of the three coupled differential Equations (17), (18), and (21) with boundary conditions (8), (9.1), and $\left(9.2^{\prime}\right)$. Given initial and boundary conditions, the model predicts time and spatial changes of ice thickness, longitudinal velocity, and deviatoric stress. Auxiliary diagnostic relations (19) and (20) provide the normal and shear stresses.

The domain up-stream of the grounding line over which this dynamic regime extends can be estimated from the ratio of shear stress to deviatoric stress; the magnitude of the former is estimated here explicitly in terms of the free surface slope $\alpha$ from Equation (20),

$$
\left|\frac{\sigma_{x y}}{\sigma_{x x}^{\prime}}\right| \approx \rho_{\mathrm{i}} g H_{\mathrm{c}} \alpha\left(\frac{A_{\mathrm{c}} L_{\mathrm{c}}}{U_{\mathrm{c}}}\right)^{1 / 3} \approx \omega^{2}\left[\frac{\Delta \rho}{\rho_{\mathrm{w}}}\right]^{-1} .
$$

Solving for $L_{\mathrm{c}}$, we have

$$
L_{\mathrm{c}} \approx\left[\frac{\Delta \rho}{\rho_{\mathrm{w}}}\right]^{-3 / 4}\left[\frac{U_{\mathrm{c}} / A_{\mathrm{c}}}{\left(\rho_{\mathrm{i}} g \alpha\right)^{3}}\right]^{1 / 4} .
$$

Since the đrstance up-stream from the grounding line over which the ratio of shearing to stretching remains small varies as the 1/4th power of the ratio of basal sliding velocity to flow-law constant, it is fairly insensitive to changes in $U_{\mathrm{c}}$ and $A_{\mathrm{c}}$. For $A_{\mathrm{c}} \approx 1 \times 10^{-17} \mathrm{a}^{-1} \mathrm{~Pa}^{-3}, U_{\mathrm{c}} \approx$ $200 \mathrm{~m} \mathrm{a}^{-1}$ and $\alpha \approx 5 \times 10^{-3}, L_{\mathrm{c}} \approx 150 \mathrm{~km}$.

Our knowledge of conditions at the base of ice streams is still limited. It does seem likely, however, that, largely as a result of strain heating and geothermal heat flux, the basal ice of most West Antarctic ice streams is at the pressure melting-point (Gow and others, 1968; Rose, 1979) and that an extensive basal water layer is present (Weertman and Birchfield, 1982). Under these conditions, the effective bed roughness is decreased and separation of the basal ice by cavity formation on the lee side of obstacles and subglacial buoyancy effects is favored, and high sliding velocities are to be expected (e.g. Paterson, 1981, chapter 7; Bindschadler, 1983). The sliding law $u=F \tau_{\mathrm{b}}{ }^{m}$ incorporates both flow around bed protuberances by creep deformation and regelation through the basal shear stress term $\tau_{b}{ }^{m}$, and subglacial water effects through the function $F$. Theoretical considerations and modeling studies indicate that $1 \leqslant m \leqslant 3$ (Weertman, 1957; Fowler, 1981; Budd and others, 1984; McInnes and Budd, 1984) and that $F$ is an inverse function of the ice thickness above buoyancy,

$$
H-\frac{\rho_{\mathrm{W}}}{\rho_{\mathrm{i}}}(h+S)
$$

(Bindschadler, 1983; Budd and others, 1984; McInnes and Budd, 1984). The role of $F$ in the dynamics of the ice stream is seen by estimating $U_{\mathrm{c}}$ in Equation (23) from Equation $(21), U_{\mathrm{c}} \approx F_{\mathrm{c}}\left(\rho_{\mathrm{i}} g H_{\mathrm{c}} \alpha\right)^{m}$

$$
L_{\mathrm{c}} \approx\left(\frac{\Delta \rho}{\rho_{\mathrm{W}}}\right]^{-3 / 4}\left[\frac{F_{\mathrm{c}}}{A_{\mathrm{c}}}\right]^{1 / 4} H_{\mathrm{c}}{ }^{m / 4}
$$

for $m \approx 3$. The distance over which the ice-stream flow regime can be maintained increases with basal lubrication $(F)$; the relative importance of shearing versus the slidinginduced stretching increases as $A$ increases, i.e. as the ice becomes softer. In the present model, $A$ should be regarded as a vertically averaged rheological constant. Inclusion of the temperature dependence of $A$ in the model would give rise to a differential softening of the ice in the basal layer compared to that in the near-surface layer (e.g. Hutter, 1983, chapter 3) and thus to a thermally induced shearing. Due to the large increase in creep-activation energy at temperatures approaching the melting point (Weertman, 1973), and to the relatively temperate surface conditions prevalent near the edges of a major polar ice sheet such as in Antarctica, this effect may be relatively insignificant compared to the large ice-shelf-induced stretching.

Using Equations (18) and (20), the basal shear stress in our model,

$$
\tau_{\mathrm{b}}=2 \sigma_{x x}^{\prime} \frac{\partial h^{\prime}}{\partial x}+\sigma_{x y}
$$

is found to be

$$
\tau_{\mathrm{b}}=\rho_{\mathrm{i}} g H \alpha+2 \frac{\partial}{\partial x}\left(H \sigma_{x x}^{\prime}\right) \equiv \tau_{\mathrm{c}}+\tau_{\mathrm{m}}
$$

where $\tau_{\mathrm{c}}=\rho_{\mathrm{i}} g H \alpha$ is the "classical" basal shear stress that exactly balances the gravitational driving stress and

$$
\tau_{\mathrm{m}}=2 \frac{\partial}{\partial x}\left(H \sigma_{x x}^{\prime}\right)
$$

is a buoyancy correction to $\tau_{\mathrm{c}}$

Since $\sigma_{x x}^{\prime}$ contains a second derivative of the surface elevation, $\tau_{\mathrm{m}}$ contains a third derivative. Because of the correction $\tau_{\mathrm{m}}$, the total basal shear stress $\tau_{\mathrm{b}}$ will now be a function not only of local conditions but also of conditions at some distance up-stream and down-stream (Budd, 1975; McMeeking and Johnson 1985). Further significance of $\tau_{\mathrm{m}}$ becomes clear if we look at the strain-rate, $\dot{\epsilon}_{x x}$, which, from Equation (18), can be approximated by $\dot{\epsilon}_{x x} \approx A \sigma_{x x}^{\prime}$. Thus,

$$
\tau_{\mathrm{m}} \approx 2 A^{-1 / 3} \frac{\partial}{\partial \mathrm{x}}\left[H \dot{\epsilon}_{x x^{1 / 3}}\right]
$$

From Equation (21), the velocity in terms of $\tau_{\mathrm{c}}$ and $\tau_{\mathrm{m}}$ is

$$
u=F\left(\tau_{\mathrm{c}}^{m}+m \tau_{\mathrm{c}}^{m-1} \tau_{\mathrm{m}}\right) \approx F\left(\tau_{\mathrm{c}}+\tau_{\mathrm{m}}\right)^{m}
$$

and hence,

$$
u=F\left[-\rho_{\mathrm{i}} g H \frac{\partial h^{\prime}}{\partial x}+2 A^{-1 / 3} \frac{\partial}{\partial x}\left[H\left(\frac{\partial u}{\partial x}\right]^{1 / 3}\right)\right]_{(27)}^{m}
$$


It is now apparent that $\tau_{\mathrm{m}}$ introduces an internal feed-back between down-stream changes in longitudinal strain-rate, ice thickness, and basal velocity. This feed-back is positive if

$$
\frac{\partial\left|\dot{\epsilon}_{x x}\right|}{\partial x}>\frac{3}{H}\left|\dot{\epsilon}_{x x} \frac{\partial H}{\partial x}\right| \text {. }
$$

The buoyancy basal shear stress $\tau_{m}$ thus provides a mechanism whereby the ice-stream profile and sliding velocity adjust to conditions at the grounding line so as to generate a stretching of the same order of magnitude as that imposed at the grounding line by the ocean or the ice shelf into which the ice stream discharges. In the absence of an ice shelf or if the ice shelf is freely floating, the down-stream strain-rate gradient is large and positive, the surface slope is small, and $\tau_{\mathrm{m}}$ is positive. If the backpressure exerted by the ice shelf increases, the ice-shelf strain-rate at the grounding line decreases and may even become negative, and there will be a region up-stream of the grounding line in which the negative feed-back associated with a negative $\tau_{\mathrm{m}}$ contributes in decreasing the sliding velocity and strain-rate in the ice stream to the grounding-line value. It is important to realize, however, that as the back-pressure changes, both $F$ and $\tau_{\text {c will also }}$ be affected; this discussion is meant only to highlight the qualitative role of $\tau_{\mathrm{m}}$ in adjusting the ice-stream sliding velocity to conditions at the grounding line. The detailed mechanism of this adjustment is explored fully in the numerical model (paper in preparation by I. Muszynski and G.E. Birchfield).

Previously published marine ice-sheet models (Thomas, 1977; Thomas and Bentley, 1978; Hughes, 1981; Stuiver and others, 1981; Young, 1981; Oerlemans, 1982[b]; Budd and others, 1984; Fastook, 1984, 1985; Lingle, 1984; McInnes and Budd, 1984; Lingle and Clark, 1985; van der Veen, unpublished) have used the "classical" sliding law $u=F \tau_{\mathrm{b}}{ }^{m}$ with $F$ derived either from theoretical considerations of the sliding process or by fitting to field data. The basal shear stress in these models is thus a function of local conditions only, and any change in back-pressure will act on the sliding velocity through the resulting changes in ice-stream thickness and surface slope only. Inclusion of $\tau_{m}$ not only ensures dynamical self-consistency but provides an explicit feed-back mechanism that links changes in back-pressure directly to changes in the ice-stream strain-rate.

Field measurements show that the surface curvature of ice streams is positive, i.e. concave up (e.g. Hughes, 1975, fig. 6; Rose, 1979, fig. 1). This was attributed by Hughes (1975) to partial uncoupling of the base of the ice stream from its bed in the presence of large amounts of basal melt water. The stress-continuity requirement at the grounding line (Equation $\left(9.2^{\prime}\right)$ ) can be rewritten as an expression for the surface curvature on the ice-stream side of the grounding line by substitution of Equation (18):

$$
-\frac{1}{\alpha} \frac{\partial \alpha}{\partial x}=-\frac{A \Sigma^{\prime * 3}}{m F T_{c}^{m}}+\left[\frac{1}{m F} \frac{\partial F}{\partial x}-\frac{\alpha-\phi}{H}\right] .
$$

The term involving the down-stream gradient of $F$ stresses the importance of subglacial water-pressure effects in maintaining positive ice-stream surface curvatures.

\section{ACKNOWLEDGEMENTS}

Part of this work was completed while the authors were visiting the Institute of Oceanographic Sciences, Wormley, England; the second author was on a Guggenheim Fellowship at the time of this visit and gratefully acknowledges the support therefrom. Appreciation is also extended to the Scott Polar Research Institute, University of Cambridge, for the use of their library. The figure was drafted by C. Cheverton. The authors are indebted to two anonymous reviewers whose comments resulted in considerable improvements to the manuscript. This research was supported by grant ATM8306251 from the Climate Dynamics Section, U.S. National Science Foundation.

\section{REFERENCES}

Bentley, C.R. 1984. Some aspects of the cryosphere and its role in climatic change. (In Hansen, J.E., and Takahashi, $\mathrm{T}$., eds. Climate processes and climate sensitivity. Washington, DC, American Geophysical Union, p. 207-20. (Geophysical Monograph 29.))

Bindschadler, R. 1983. The importance of pressurized subglacial water in separation and sliding at the glacier bed. Journal of Glaciology, Vol. 29, No. 101, p. 3-19.

Birchfield, G.E., and Grumbine, R.W. 1985. "Slow" physics of large continental ice sheets and underlying bedrock and its relation to the Pleistocene ice ages. Journal of Geophysical Research, Vol. 90, No. B13, p. 11,294-302.

Birchfield, G.E., and others. 1981. A paleoclimate model of northern hemisphere ice sheets, by G.E. Birchfield, J. Weertman, and A.T. Lunde. Quaternary Research, Vol. 15, No. 2 , p. $126-42$

Bowman, K.P. 1982. Sensitivity of an annual mean diffusive energy balance model with an ice sheet. Journal of Geophysical Research, Vol. 87, No. C12, p. 9667-74.

Boyle, E.A., and Keigwin, L.D. 1982. Deep circulation of the North Atlantic over the last 200,000 years: geochemical evidence. Science, Vol. 218, No. 4574, p. 784-87.

Broecker, W.S. 1984. Terminations. (In Berger, A., and others, eds. Milankovitch and climate. Part 2. Edited by A. Berger, J. Imbrie, J. Hays, G. Kukla, and B. Saltzman. Dordrecht, D. Reidel Publishing Co., p. 687-98. (NATO ASI, Ser. C, Vol. 126.))

Broecker, W.S., and Takahashi, T. 1984. Is there a tie between atmospheric $\mathrm{CO}_{2}$ content and oceanic circulation? (In Hansen, J.E., and Takahashi, T., eds. Climate processes and climate sensitivity. Washington, DC, American Geophysical Union, p. 314-26. (Geophysical Monograph 29.))

Budd, W.F. 1975. A first simple model for periodically self-surging glaciers. Journal of Glaciology, Vol. 14, No. 70 , p. 3-21.

Budd, W.F., and others. 1984. A three-dimensional time-dependent model of the West Antarctic ice sheet, by W.F. Budd, D. Jenssen, and I.N. Smith. Annals of Glaciology, Vol. 5, p. 29-36.

Budyko, M.I. 1969. The effect of solar radiation variations on the climate of the Earth. Tellus, Vol. 21, No. 5, p. 611-19.

Crabtree, R.D., and Doake, C.S.M. 1982. Pine Island Glacier and its drainage basin: results from radio echo-sounding. Annals of Glaciology, Vol. 3, p. 65-70.

Denton, G.H., and Hughes, T.J. 1983. Milankovitch theory of ice ages: hypothesis of ice-sheet linkage between regional insolation and global climate. Quaternary Research, Vol. 20, No. 2, p. 125-44.

Dickinson, R.E. 1985. Climate sensitivity. Advances in Geophysics, Vol. 28A, p. 99-129.

Doake, C.S.M. 1985. Antarctic mass balance: glaciological evidence from Antarctic Peninsula and Weddell Sea sector (In Glaciers, ice sheets, and sea level: effect of a $\mathrm{CO}_{2}$-induced climatic change. Report of a workshop held in Seattle, Washington, September 13-15, 1984. Washington, DC, U.S. Department of Energy, p. 197-209.)

Ennever, F.K., and McElroy, M.B. 1985. Changes in atmospheric $\mathrm{CO}_{2}$ : factors regulating the glacial to interglacial transition. (In Sundquist, E.T., and Broecker, W.S., eds. The carbon cycle and atmospheric $\mathrm{CO}_{2}$ : natural variations Archean to present. Washington, DC, American Geophysical Union, p. 154-62. (Geophysical Monograph 32.))

Fastook, J.L. 1984. West Antarctica, the sea-level controlled marine instability: past and future. (In Hansen, J.E., and Takahashi, T., eds. Climate processes and climate sensitivity. Washington, DC, American Geophysical Union, p. 275-87. (Geophysical Monograph 29.))

Fastook, J.L. 1985. Ice shelves and ice streams: three modeling experiments. (In Glaciers, ice sheets, and sea level: effect of a $\mathrm{CO}_{2}$-induced climatic change. Report of a workshop held in Seattle, Washington. September 13-15, 1984. Washington, DC, U.S. Department of Energy, p. 279-300.) 
Fowler, A.C. 1981. A theoretical treatment of the sliding of glaciers in the absence of cavitation. Philosophical Transactions of the Royal Society of London, Ser. A, Vol. 298 , No. 1445 , p. 637-85.

Glen, J.W. 1955. The creep of polycrystalline ice. Proceedings of the Royal Society of London, Ser. A, Vol. 228 , No. 1175 , p. 519-38.

Gow, A.J., and others. 1968. Antarctic ice sheet: preliminary results of first core hole to bedrock, by A.J. Gow, H.T. Ueda, and D.E. Garfield. Science, Vol. 161, No. 3845, p. 1011-13.

Hartmann, D.L. 1984. On the role of global-scale waves in ice-albedo and vegetation-albedo feedback. (In Hansen, J.E., and Takahashi, $\mathrm{T}$., eds. Climate processes and climate sensitivity. Washington, DC, American Geophysical Union, p. 18-28. (Geophysical Monograph 29.))

Hays, J.D., and others. 1976. Variations in the Earth's orbit: pacemaker of the ice ages, by J.D. Hays, J. Imbrie, and N.J. Shackleton. Science, Vol. 194, No. 4270, p. 1121-32.

Hughes, T.J. 1973. Is the West Antarctic ice sheet disintegrating? Journal of Geophysical Research, Vol. 78, No. 33, p. 7884-910.

Hughes, T.J. 1975. The West Antarctic ice sheet: instability, disintegration, and initiation of ice ages. Reviews of Geophysics and Space Physics, Vol. 13, No. 4, p. 502-26.

Hughes, T.J. 1977. West Antarctic ice streams. Reviews of Geophysics and Space Physics, Vol. 15, No. 1, p. 1-46.

Hughes, T.J. 1981. Numerical reconstruction of paleo-ice sheets. (In Denton, G.H., and Hughes, T.J., eds. The last great ice sheets. New York, etc., John Wiley and Sons, p. 221-61.)

Hughes, T.J. 1982. On the disintegration of ice shelves: the role of thinning. Annals of Glaciology, Vol. 3, p. 146-51.

Hughes, T. 1986. The Jakobshavns effect. Geophysical Research Letters, Vol. 13, No. 1, p. 46-48.

Hutter, K. 1981. The effect of longitudinal strain on the shear stress of an ice sheet: in defence of using stretched coordinates. Journal of Glaciology, Vol. 27, No. 95, p. 39-56.

Hutter, K. 1983. Theoretical glaciology; material science of ice and the mechanics of glaciers and ice sheets. Dordrecht, etc., D. Reidel Publishing Company/Tokyo, Terra Scientific Publishing Company.

Imbrie, J. 1985. A theoretical framework for the Pleistocene ice ages. Journal of the Geological Society, Vol. 142, p. 417-32.

Imbrie, J., and Imbrie, K.P. 1979. Ice ages: solving the mystery. Hillside, NJ., Enslow.

Jacobs, S.S. 1985. Oceanographic evidence for land ice/ocean interactions in the Southern Ocean. (In Glaciers, ice sheets, and sea level: effect of a $\mathrm{CO}_{2}$-induced climatic change. Report of a workshop held in Seattle, Washington, September 13-15, 1984. Washington, DC, U.S. Department of Energy, p. 116-28.)

Johnson, I.R. 1981. The steady profile of an axisymmetric ice sheet. Journal of Glaciology, Vol. 27, No. 95, p. 25-37.

Le Treut, H., and Ghil, M. 1983. Orbital forcing, climatic interactions, and glaciation cycles. Journal of Geophysical Research, Vol. 88, No. C9, p. 5167-90.

Lingle, C.S. 1984. A numerical model of interactions between a polar ice stream and the ocean: application to Ice Stream E, West Antarctica. Journal of Geophysical Research, Vol. 89, No. C3, p. 3523-49.

Lingle, C.S., and Clark, J.A. 1985. A numerical model of interactions between a marine ice sheet and the solid earth: application to a West Antarctic ice stream. Journal of Geophysical Research, Vol. 90, No. C1, p. 1100-14.

MacAyeal, D.R. 1984. Thermohaline circulation below the Ross Ice Shelf: a consequence of tidally induced vertical mixing and basal melting. Journal of Geophysical Research, Vol. 89, No. C1, p. 597-606.

MacAyeal, D.R. Unpublished. Tidal-current rectification and tidal mixing fronts: controls on the Ross Ice Shelf flow and mass balance. [Ph.D. thesis, Princeton University, 1983.]

McInnes, B.J., and Budd, W.F. 1984. A cross-sectional model for West Antarctica. Annals of Glaciology, Vol. 5, p. 95-99.
McMeeking, R.M., and Johnson, R.E. 1985. On the analysis of longitudinal stress in glaciers. Journal of Glaciology, Vol. 31, No. 109, p. 293-302.

McMeeking, R.M., and Johnson, R.E. 1986. On the mechanics of surging glaciers. Journal of Glaciology, Vol. 32 , No. 110 , p. $120-32$.

Manabe, S., and Broccoli, A.J. 1985[a]. A comparison of climate model sensitivity with data from the last glacial maximum. Journal of the Atmospheric Sciences, Vol. 42, No. 23 , p. $2643-51$.

Manabe, S., and Broccoli, A.J. 1985[b]. The influence of continental ice sheets on the climate of an ice age Journal of Geophysical Research, Vol. 90, No. D1, p 2167-90.

Mercer, J.H. 1978. West Antarctic ice sheet and $\mathrm{CO}_{2}$ greenhouse effect: a threat of disaster. Nature, Vol. 271, No. 5643 , p. $321-25$.

Mercer, J.H. 1984. Simultaneous climatic change in both hemispheres and similar bipolar interglacial warming: evidence and implications. (In Hansen, J.E., and Takahashi, T., eds. Climate processes and climate sensitivity. Washington, DC, American Geophysical Union, p. 307-13. (Geophysical Monograph 29.))

Morland, L.W., and Johnson, I.R. 1980. Steady motion of ice sheets. Journal of Glaciology, Vol. 25, No. 92, p. 229-46.

Morland, L.W., and Johnson, I.R. 1982. Effects of bed inclination and topography on steady isothermal ice sheets. Journal of Glaciology, Vol. 28, No. 98, p. 71-90.

Muszynski, I., and Birchfield, G.E. 1985. The dependence of Antarctic accumulation rates on surface temperature and elevation. Tellus, Vol. 37A, p. 204-08

National Research Council. 1985. Glaciers, ice sheets, and sea level: effect of a $\mathrm{CO}_{2}$-induced climatic change. Report of a workshop held in Seattle, Washington, September 13-15, 1984. Washington, DC, U.S. Department of Energy.

Nayfeh, A. 1973. Perturbation methods. New York, J. Wiley and Sons.

North, G.R., and others. 1981. Energy-balance climate models, by G.R. North, R.F. Cahalan, and J.A. Coakley. Reviews of Geophysics and Space Physics, Vol. 19, p. 91-122.

Oerlemans, J, 1980. Model experiments on the 100,000-yr glacial cycle. Nature, Vol. 287 , No. 5781 , p. 430-32.

Oerlemans, J. 1982[a]. Glacial cycles and ice-sheet modelling. Climatic Change, Vol. 4, No. 4, p. 353-74.

Oerlemans, J. 1982[b]. Response of the Antarctic ice sheet to a climatic warming: a model study. Journal of Climatology, Vol. 2, No. 1, p. 1-11.

Paterson, W.S.B. 1981. The physics of glaciers. Second edition. Oxford, etc., Pergamon Press. (Pergamon International Library.)

Peltier, W.R., and Hyde, W. 1984. A model of the ice age cycle. (In Berger, A., and others, eds. Milankovitch and climate. Part 2. Edited by A. Berger, J. Imbrie, J. Hays, G. Kukla, and B. Saltzman. Dordrecht, D. Reidel Publishing Co., p. 565-80. (NATO ASI, Ser. C, Vol. 126.))

Pollard, D. 1982. A simple ice sheet model yields realistic 100 kyr glacial cycles. Nature, Vol. 296, No. 5855, p. 334-38.

Pollard, D. 1984. Some ice-age aspects of a calving ice-sheet model. (In Berger, A., and others, eds. Milankovitch and climate. Part 2. Edited by A. Berger, J. Imbrie, J. Hays, G. Kukla, and B. Saltzman. Dordrecht, D. Reidel Publishing Co., p. 541-64. (NATO ASI, Ser. C, Vol. 126.))

Rose, K.E. 1979. Characteristics of ice flow in Marie Byrd Land, Antarctica. Journal of Glaciology, Vol. 24, No. 90, p. 63-75.

Ruddiman, W.F., and McIntyre, A. 1981[a]. Oceanic mechanisms for amplification of the 23,000-year ice-volume cycle. Science, Vol. 212, No. 4495, p. 617-27

Ruddiman, W.F., and McIntyre, A. 1981[b]. The mode and mechanism of the last deglaciation: oceanic evidence. Quaternary Research, Vol. 16, No, 2, p. 125-34

Saltzman, B. 1983. Climatic systems analysis. Advances in Geophysics, Vol. 25, p. 173-233. 
Saltzman, B., and others. 1982. A possible marine mechanism for internally generated long-period climate cycles, by B. Saltzman, A. Sutera, and A.R. Hansen. Journal of the Atmospheric Sciences, Vol. 39, p. 2634-37.

Sanderson, T.J.O. 1979. Equilibrium profile of ice shelves. Journal of Glaciology, Vol. 22, No. 88, p. 435-60.

Schneider, S.H., and Dickinson, R.E. 1974. Climate modeling. Reviews of Geophysics and Space Physics, Vol. 12 , p. 447-93.

Schwerdtfeger, W. 1970. The climate of the Antarctic. (In Orvig, S., ed. Climates of the polar regions. Amsterdam, etc., Elsevier Publishing Co., p. 253-355. (World Survey of Climatology Vol. 14.))

Sellers, W.D. 1969. A global climate model based on the energy balance of the earth-atmosphere system. Journal of Applied Meteorology, Vol. 8, p. 392-400.

Shoemaker, E.M., and Morland, L.W. 1984. A glacier flow model incorporating longitudinal deviatoric stress. Journal of Glaciology, Vol. 30, No. 106, p. 334-40.

Stuiver, M., and others. 1981. History of the marine ice sheet in West Antarctica during the last glaciation: a working hypothesis, by M. Stuiver, G.H. Denton, T.J. Hughes, and J.L. Fastook. (In Denton, G.H., and Hughes, T.J., eds. The last great ice sheets. New York, etc., John Wiley \& Sons, p. 319-436.)

Thomas, R.H. 1973. The creep of ice shelves: theory. Journal of Glaciology, Vol. 12, No. 64, p. 45-53.

Thomas, R.H. 1976. Thickening of the Ross Ice Shelf and equilibrium state of the West Antarctic ice sheet. Nature, Vol. 259, No. 5540 , p. $180-83$.

Thomas, R.H. 1977. Calving bay dynamics and ice sheet retreat up the St. Lawrence valley system. Géographie Physique et Quaternaire, Vol. 31, Nos. 3-4, p. 347-56.

Thomas, R.H. 1979[a]. Ice shelves: a review. Journal of Glaciology, Vol. 24, No. 90, p. 273-86

Thomas, R.H. 1979[b]. The dynamics of marine ice sheets. Journal of Glaciology, Vol. 24, No. 90, p. 167-77.

Thomas, R.H. 1984. Ice sheet margins and ice shelves. (In Hansen, J.E., and Takahashi, T., eds. Climate processes and climate sensitivity. Washington, DC, American Geophysical Union, p. 265-74. (Geophysical Monograph 29.))

Thomas, R.H. 1985. Responses of the polar ice sheets to climatic warming. (In Glaciers, ice sheets, and sea level: effect of a $\mathrm{CO}_{2}$-induced climatic change. Report of $a$ workshop held in Seattle, Washington, September 13-15, 1984. Washington, DC, U.S. Department of Energy, p. 301-16.)

Thomas, R.H., and Bentley, C.R. 1978. A model for Holocene retreat of the West Antarctic ice sheet. Quaternary Research, Vol. 10, No. 2, p. 150-70.

Toggweiler, J.R., and Sarmiento, J.L. 1985. Glacial to interglacial changes in atmospheric carbon dioxide: the critical role of ocean surface water in high latitudes. (In Sundquist, E.T., and Broecker, W.S., eds. The carbon cycle and atmospheric $\mathrm{CO}_{2}$ : natural variations Archean to present. Washington, DC, American Geophysical Union, p. 163-84. (Geophysical Monograph 32.))

Veen, C.J. van der. Unpublished. Ice sheets, atmospheric $\mathrm{CO}_{2}$ and sea level. [Ph.D. thesis, Rijksuniversiteit Utrecht, Utrecht, 1986.]

Weertman, J. 1957. Deformation of floating ice shelves. Journal of Glaciology, Vol. 3, No. 21, p. 38-42.

Weertman, J. 1973. Creep of ice. (In Whalley, E., and others, eds. Physics and chemistry of ice. Edited by E. Whalley, S.J. Jones, and L.W. Gold. Ottawa, Royal Society of Canada, p. 320-37.)

Weertman, J. 1974. Stability of the junction of an ice sheet and an ice shelf. Journal of Glaciology, Vol. 13, No. 67, p. 3-11.

Weertman, J., and Birchfield, G.E. 1982. Subglacial water flow under ice streams and West Antarctic ice-sheet stability. Annals of Glaciology, Vol. 3, p. 316-20.

Weertman, J., and Birchfield, G.E. 1983. Basal water film, basal water pressure, and velocity of traveling waves on glaciers. Journal of Glaciology, Vol. 29, No. 101, p. 20-27.

Wenk, T., and Siegenthaler, U. 1985. The high-latitude ocean as a control of atmospheric $\mathrm{CO}_{2}$. (In Sundquist, E.T., and Broecker, W.S., eds. The carbon cycle and atmospheric $\mathrm{CO}_{2}:$ natural variations Archean to present. Washington, DC, American Geophysical Union, p. 185-94. (Geophysical Monograph 32.))

Young, N.W. 1981. Responses of ice sheets to environmental changes. [Union Géodésique et Géophysique Internationale. Association Internationale des Sciences Hydrologiques.] Sea level, ice, and climatic change. Proceedings of the symposium held 7-8 December 1979 during the 17 th general assembly of the International Union of Geodesy and Geophysics, Canberra, p. 331-60. (IAHS Publication No. 131.)

\section{APPENDIX A}

\section{SCALE ANALYSIS}

We use the approach of asymptotic analysis (Morland and Johnson, 1980, 1982; Hutter, 1981, 1983; Johnson, 1981; Shoemaker and Morland, 1984; McMeeking and Johnson, 1985 ) to develop a greatly simplified but dynamically consistent ice-stream-ice-shelf model based on the scale analysis in the text. The basic system of equations is nondimensionalized with a set of characteristic scales $X_{\mathrm{c}}$ such that the non-dimensional form of a variable $X$ is given by $\hat{X}=X / X_{\mathrm{c}}$. Since the ice stream is coupled to an ice shelf, it is natural to choose values typical of the grounding line region for the $X_{\mathrm{c}}$. The physical dimensions of the ice stream are scaled by the length over which the ice-stream flow regime extends, $L_{\mathrm{c}}$, and by a characteristic groundingline thickness, $H_{\mathrm{c}}$

Let

$$
x=L_{\mathrm{c}} \hat{x} \quad y=H_{\mathrm{c}} \hat{y}
$$

$$
\begin{gathered}
\left(h^{\prime}, \ddot{h}, H, S\right)=H_{\mathrm{c}}\left(\hat{h}^{\prime}, \hat{h}, \hat{H}, \hat{S}\right) \quad\left(x^{*}, L\right)=L_{\mathrm{c}}\left(\hat{x^{*}}, \hat{L}\right) \\
\left(\sigma_{i j}, \sigma_{i i}^{\prime}, \Sigma^{*}\right)=\sigma_{\mathrm{c}}\left(\hat{\sigma}_{i j}, \hat{\sigma}_{i i}^{\prime}, \hat{\Sigma}^{*}\right) \quad A=A_{\mathrm{c}} \hat{A} \\
(u, v)=U_{\mathrm{c}}(\hat{u}, \hat{v}) \quad(a, b)=\omega^{2} U_{\mathrm{c}}(\hat{a}, \hat{b}) \\
t=\frac{\hat{t}}{\dot{\epsilon}_{\mathrm{c}}}=\frac{L_{\mathrm{c}}}{U_{\mathrm{c}}} \hat{t} \quad F=F_{\mathrm{c}} \hat{F} .
\end{gathered}
$$

We scale all stresses with

$$
\sigma_{\mathrm{c}}=\rho_{\mathrm{i}} g H_{\mathrm{c}} .
$$

Since the empirical function $F$ in the basal sliding law is the ratio of the velocity to a power of the basal shear stress, we scale $F$ as the ratio of these two quantities,

$$
F_{\mathrm{c}}=\frac{U_{\mathrm{c}}}{\omega^{2 m_{\sigma_{\mathrm{c}}}}} .
$$

The characteristic strain-rate in the ice shelf is

$$
\dot{\epsilon}_{\mathrm{c}}=A_{\mathrm{c}}\left[\frac{\Delta \rho}{\rho_{\mathrm{w}}} \sigma_{\mathrm{c}}\right]^{3} .
$$

From continuity, the characteristic velocity for the ice stream is then

$$
U_{\mathrm{c}}=A_{\mathrm{c}} L_{\mathrm{c}}\left[\frac{\Delta \rho}{\rho_{\mathrm{w}}} \sigma_{\mathrm{c}}\right]^{3}:
$$

Substituting for all dimensional variables in terms of characteristic quantities and non-dimensional variables, we obtain the following system of equations and boundary conditions:

$$
\begin{aligned}
& \frac{\partial \hat{H}}{\partial \hat{t}}+\frac{\partial}{\partial \hat{x}}(\hat{H} \hat{u})=\hat{a}-\hat{b} \\
& \frac{\partial \hat{\sigma}_{x x}}{\partial \hat{x}}+\frac{1}{\omega^{2}} \frac{\partial \hat{\sigma}_{x y}}{\partial \hat{y}}=0,
\end{aligned}
$$




$$
\begin{gathered}
\frac{\partial \hat{\sigma}_{x y}}{\partial \hat{x}}+\frac{1}{\omega^{2}} \frac{\partial \hat{\sigma}_{y y}}{\partial \hat{y}}=\frac{1}{\omega^{2}}, \\
\hat{\sigma}_{x x}^{\prime}=\frac{1}{2}\left(\hat{\sigma}_{x x}-\hat{\sigma}_{y y}\right), \\
\hat{\tau}^{2}=\hat{\sigma}_{x x}^{\prime}+\hat{\sigma}_{x y}{ }^{2}, \\
\frac{\partial \hat{u}}{\partial \hat{x}}=\left[\frac{\Delta \rho}{\rho_{\mathrm{w}}}\right]^{-3} A \hat{\tau}^{2} \hat{\sigma}_{x x}^{\prime}, \\
\frac{1}{\omega^{2}} \frac{\partial \hat{u}}{\partial \hat{y}}=-\frac{\partial \hat{u}}{\partial \hat{x}}, \\
\frac{\partial \hat{v}}{\partial \hat{x}}+\frac{1}{\omega^{2}} \frac{\partial \hat{u}}{\partial \hat{y}}=2\left[\frac{\Delta \rho}{\rho_{\mathrm{w}}}\right]^{-3} \hat{A} \hat{\tau}^{2} \hat{\sigma}_{x y}
\end{gathered}
$$

with boundary conditions

at $\hat{y}=\hat{h}^{\prime}$ :

$$
\begin{aligned}
& -\omega^{2} \hat{\sigma}_{x x} \frac{\partial \hat{h}^{\prime}}{\partial x}+\hat{\sigma}_{x y}=0, \\
& -\omega^{2} \hat{\sigma}_{x y} \frac{\partial \hat{h}^{\prime}}{\partial \hat{x}}+\hat{\sigma}_{y y}=0, \\
& \frac{\hat{v}}{\omega^{2}}=\frac{\partial \hat{h}^{\prime}}{\partial \hat{t}}+\hat{u} \frac{\partial \hat{h}^{\prime}}{\partial \hat{x}}-\hat{a},
\end{aligned}
$$

at $\hat{y}=-\hat{h}$ :

$$
\hat{u}=\hat{F}\left[2 \hat{\sigma}_{x x}^{\prime} \frac{\partial \hat{h}}{\partial \hat{\lambda}}+\frac{1}{\omega^{2}} \hat{\sigma}_{x y}\right]^{m},
$$

at $\hat{x}=0$ :

$$
\begin{aligned}
& \hat{H}=\hat{H}_{00}, \\
& \hat{M}=\hat{M}_{00},
\end{aligned}
$$

at $\hat{x}=\hat{x}^{*}$ :

$$
\begin{gathered}
\frac{\Delta \rho}{\rho_{\mathrm{w}}} \hat{H}^{*}=\hat{h}^{*}-\hat{S}, \\
\hat{\sigma}_{x x}=\hat{\Sigma}^{*} .
\end{gathered}
$$

As shown in the text, for predominance of stretching over shearing, $\omega^{2} \ll \Delta \rho / \rho_{w}$, the latter ratio being a constant of our problem. For all ice streams of interest to us, the relationship $\omega \approx \Delta \rho / \rho_{w} \leqslant 10^{-1}$ is valid and will be used to simplify the scale analysis.

Based on the analysis in the text, we now incorporate explicit statements as to the relative magnitudes of normal, shear, and deviatoric stresses and of normal and shear strain-rates into the equations by expanding all dependent variables in $n$-term asymptotic series of the form

$$
\hat{X}=\sum_{m=m_{0}}^{m=n-1} \omega^{m} \hat{X}_{m}+O\left(\omega^{n}\right)
$$

(for example, see Nayfeh, 1973) where the $O$ symbol means that the error, $T$, committed by truncating the series after $m=(n-1)$ terms is such that

$$
\lim _{\omega \rightarrow 0} \frac{T}{\omega^{m}}<\infty
$$

If $m_{0}=0$, the leading term in the asymptotic expansion for $X$ is $\hat{X}_{0}, \hat{X} \approx O(1)$ or $X \approx X_{\mathrm{c}}$. If $m_{0}=1$, then $X \approx$ $\omega X_{c}$ and if $m_{0}=2$ then $X \approx \omega^{2} X_{c}$. Clearly, the normal stresses $\approx O(1)\left(m_{0}=0\right)$; it is then appropriate to let the deviatoric stresses and the effective shear stress $\approx O(\omega)$ $\left(m_{0}=1\right)$ and, as suggested by Equation (A6.1), the shear stress $\approx O\left(\omega^{2}\right) \quad\left(m_{0}=2\right)$. By definition of $U_{\mathrm{c}}$ and $F_{\mathrm{c}}$, $(u, F) \approx O(1)\left(m_{0}=0\right)$, while Equation (A6.3) indicates that $v \approx O\left(\omega^{2}\right)\left(m_{0}=2\right)$. Since the ice-surface elevation is unknown, we expand $h^{\prime}$ and $H$ in asymptotic series with $m_{0}=0$; although we do not model the bedrock response, $h$, for homogeneity of notation, we write $\hat{h}=\hat{h}_{0}, \hat{h}_{m}=0$ $(m \neq 0)$. The top boundary conditions, Equations (A6), require the values of stresses and velocities at the unknown surface $\hat{y}=\hat{h}^{\prime}$. These conditions are transformed into boundary conditions applied at $\hat{y}=\hat{h}_{0}^{\prime}$ by expanding the stresses and velocities in Taylor series about $\hat{y}=\hat{h}_{0}^{\prime}$.

\section{SCALED EQUATIONS}

We now replace all variables by their asymptotic expansions and group terms according to powers of $\omega$. Since the resulting equations are valid for any value of $\omega$, the coefficients of $\omega$ have to vanish separately. By equating the coefficients of successive powers of $\omega$ to zero, the original system of equations is separated into a hierarchy of equations representing successively smaller corrections to the lowest-order system obtained by setting $\omega$ equal to zero. The zero-order system can be written

$$
\begin{gathered}
\frac{\partial \hat{H}_{0}}{\partial \hat{t}}+\frac{\partial}{\partial \hat{x}}\left(\hat{H}_{\partial \hat{H}_{0}}\right)=\hat{a}-\hat{b}, \\
\frac{\partial \hat{\sigma}_{x x_{0}}}{\partial \hat{x}}+\frac{\partial \hat{\sigma}_{x y_{2}}}{\partial \hat{y}}=0, \\
\frac{\partial \hat{\sigma}_{y y_{0}}}{\partial \hat{y}}=1,
\end{gathered}
$$

$$
\hat{\sigma}_{x x_{0}}=\hat{\sigma}_{y y_{0}},
$$

$$
\frac{\partial \hat{u}_{0}}{\partial \hat{x}}=\hat{A} \hat{\sigma}_{x x_{1}^{\prime}}^{3}
$$

$$
\frac{\partial \hat{u}_{0}}{\partial \hat{y}}=0
$$

with boundary conditions

at $\hat{y}=\hat{h}_{0}^{\prime}$ :

$$
\begin{gathered}
-\hat{\sigma}_{x x_{0}} \quad \frac{\partial \hat{h}_{0}^{\prime}}{\partial \hat{x}}+\hat{\sigma}_{x y_{2}}=0, \\
\hat{\sigma}_{y y_{0}}=0,
\end{gathered}
$$

at $\hat{y}=-\hat{h}_{0}$ :

$$
\hat{u}_{0}=\hat{F}_{0} \hat{\sigma}_{x y_{2}}^{m} \text {. }
$$

Equations (A11)-(A15) may be reduced to:

$$
\hat{\sigma}_{x x_{0}}=\hat{\sigma}_{y y_{0}}=-\left(\hat{h}_{0}^{\prime}-\hat{y}\right) \text {, }
$$




$$
\begin{gathered}
\hat{\sigma}_{x y_{2}}=-\left(\hat{h}_{0}^{\prime}-\hat{y}\right) \frac{\partial \hat{h}_{\hat{h}}^{\prime},}{\partial \hat{x}}, \\
\hat{u}_{0}=\hat{F}_{0}\left[-\hat{H}_{0} \frac{\partial \hat{h}_{0}^{\prime}}{\partial x}\right]^{m}, \\
\hat{\sigma}_{x x_{1}}^{\prime}=\frac{1}{\hat{A}^{1 / 3}}\left[\frac{\partial}{\partial \hat{x}} \hat{F}_{0}\left[-\hat{H}_{0} \frac{\partial \hat{h}_{0}^{\prime}}{\partial \hat{x}}\right]^{m}\right]^{1 / 3} .
\end{gathered}
$$

Equations (A16)-(A19), with (A10), constitute the zeroorder solution. The first-order system is then

$$
\begin{gathered}
\frac{\partial \hat{H}_{1}}{\partial \hat{t}}+\frac{\partial}{\partial \hat{x}}\left(\hat{H}_{0} \hat{u}_{1}+\hat{H}_{1} \hat{u}_{0}\right)=0, \\
\frac{\partial \hat{\sigma}_{x x_{1}}}{\partial \hat{x}}+\frac{\partial \hat{\sigma}_{x y_{3}}}{\partial \hat{y}}=0, \\
\frac{\partial \hat{\sigma}_{y y_{1}}}{\partial \hat{y}}=0, \\
\hat{\sigma}_{x x_{1}}-\hat{\sigma}_{y y_{1}}=2 \hat{\sigma}_{x x_{1}}^{\prime}, \\
\frac{\partial \hat{u}_{1}}{\partial \hat{y}}=0
\end{gathered}
$$

with boundary conditions

at $\hat{y}=\hat{h}_{0}^{\prime}$ :

$$
\begin{gathered}
-\hat{\sigma}_{x x_{1}} \frac{\partial \hat{h}_{0}^{\prime}}{\partial \hat{x}}+\hat{\sigma}_{x y_{3}}=0, \\
\hat{\sigma}_{y y_{1}}+\hat{h}_{1}^{\prime}=0,
\end{gathered}
$$

at $\hat{y}=-\hat{h}_{0}$ :

$$
\hat{u}_{1}=\hat{g}_{x y_{2}}^{m-1}\left[\hat{F}_{1} \hat{g}_{x y_{2}}+m \hat{F}_{0}\left[2 \hat{\sigma}_{x x_{1}}^{\prime} \frac{\partial \hat{h}_{0}}{\partial \hat{x}}+\hat{\sigma}_{x y_{3}}\right]\right] \text {. }
$$

The solution of this system is again straightforward: $\hat{\sigma}_{y y_{1}}=-\hat{h}_{1}^{\prime}:$

$$
\begin{gathered}
\hat{\sigma}_{x x_{1}}=2 \hat{\sigma}_{x x_{1}}^{\prime}-\hat{h}_{1}^{\prime}, \\
\hat{\sigma}_{x y_{3}}=2 \frac{\partial}{\partial \hat{x}}\left[\left(\hat{h}_{0}^{\prime}-\hat{y}\right) \hat{q}_{x x_{1}}^{\prime}\right]-\frac{\partial}{\partial \hat{x}}\left[\hat{h}_{1}^{\prime}\left(\hat{h}_{0}^{\prime}-\hat{y}\right)\right], \\
\hat{u}_{1}=\hat{\sigma}_{x y_{2}}^{m-1}\left\{\hat{F}_{1} \hat{\sigma}_{x y_{2}}+m \hat{F}_{0}\left[2 \frac{\partial}{\partial \hat{x}}\left(\hat{H}_{0} \hat{\sigma}_{x x_{1}}^{\prime}\right)-\right.\right. \\
\left.\left.-\hat{h}_{1}^{\prime} \frac{\partial \hat{h}_{0}^{\prime}}{\partial \hat{x}}-\hat{H}_{0} \frac{\partial \hat{h}_{1}^{\prime}}{\partial \hat{x}}\right]\right\} .
\end{gathered}
$$

Adding the zero- and first-order solutions, we can write the non-dimensional equations to $O\left(\omega^{2}\right)$ as

$$
\frac{\partial \hat{H}}{\partial \hat{t}}+\frac{\partial}{\partial \hat{x}}(\hat{H} \hat{u})-(\hat{a}-\hat{b})=O\left(\omega^{2}\right)
$$

$$
\begin{gathered}
\hat{\sigma}_{x x}^{\prime}=\frac{\omega}{\hat{A}^{1 / 3}}\left[\frac{\partial}{\partial \hat{x}} \hat{F}\left[-\hat{H} \frac{\partial \hat{h}^{\prime}}{\partial \hat{x}}\right]^{m}\right]^{1 / 3}+O\left(\omega^{2}\right) \\
\hat{\sigma}_{x x}=-\left(\hat{h}^{\prime}-\hat{y}\right)+2 \hat{\sigma}_{x x}^{\prime}+O\left(\omega^{2}\right) \quad \text { (A31) } \\
\hat{\sigma}_{x y}=-\omega^{2}\left(\hat{h}^{\prime}-\hat{y}\right) \frac{\partial \hat{h}^{\prime}}{\partial \hat{x}}+2 \omega^{2} \frac{\partial}{\partial \hat{x}}\left[\left(\hat{h}^{\prime}-\hat{y}\right) \hat{\sigma}_{x x}^{\prime}\right]+O\left(\omega^{4}\right) \\
\hat{u}=\hat{F}\left[-\hat{H} \frac{\partial \hat{h}^{\prime}}{\partial \hat{x}}\right]^{m-1}\left[-\hat{H} \frac{\partial \hat{h}^{\prime}}{\partial \hat{x}}+2 m \frac{\partial}{\partial \hat{x}}\left(\hat{H} \hat{\sigma}_{x x}^{\prime}\right)\right]+O\left(\omega^{2}\right) .
\end{gathered}
$$

Finally, applying the transformation $X=X_{\mathrm{c}} \hat{X}$, we obtain the dimensional form of the model equations, Equations (17) $-(21)$, which, together with boundary conditions (8) and (9), describe the marine ice-stream flow to $O\left(\omega^{2}\right)$.

\section{APPENDIX B}

\section{A SCALED ICE-SHELF MODEL}

\section{Scale analysis}

We first perform the coordinate translation $\xi=x, \eta=$ $y-S$. The upper ice surface is now given by $\underline{h}^{\prime}=h^{\prime}-S$, the lower ice surface by $\underline{h}=h+S$. The ratio $\Delta \rho / \rho_{\mathrm{i}} \approx \Delta \rho / \rho_{\mathrm{w}} \approx 10^{-1}$ is a physical constant of the problem and relates the ice thicknesses above and below sea-level, $\underline{h}^{\prime}=\Delta \rho / \rho_{\mathrm{i}} \underline{h}$. Non-dimensionalization proceeds as for the ice stream, with the characteristic length scale now being representative of the length of the ice shelf. For the velocity scale, we choose $U_{\mathrm{c}}=A_{\mathrm{c}} L_{\mathrm{c}}\left(\Delta \rho / \rho_{\mathrm{i}} \sigma_{\mathrm{c}}\right)^{3}$. For all ice shelves of interest, the relationship $\omega \leqslant \Delta \rho / \rho_{i}$ is valid and is used to simplify the analysis.

The dependent variables are next expanded in $n$-term asymptotic series in $\omega$. The expansions for the stresses and velocities are identical to those for the marine ice stream. The ice thicknesses are expanded as

$$
\begin{gathered}
(\underline{\hat{h}}, \hat{H})=\left(\underline{\hat{h}}_{0}, \hat{H}_{0}\right)+\omega\left(\underline{\underline{h}}_{1}, \hat{H}_{1}\right)+O\left(\omega^{2}\right), \\
\hat{\underline{h}}^{\prime}=\omega \hat{\hat{h}}_{1}^{\prime}+\omega^{2} \hat{\underline{h}}_{2}^{\prime}+O\left(\omega^{3}\right) .
\end{gathered}
$$

The top and bottom boundary conditions and the integral over the ice thickness in the boundary condition at the front of the ice shelf (Equation (13)) are then expanded in Taylor series about $\hat{\eta}=0$ and $\hat{\eta}=-\hat{\underline{h}}_{0}$. We now separately solve the zero- and first-order sub-systems. The continuity equation, which is not amenable to an analytical solution, and the boundary conditions at the grounding line (Equation (12)) will be added later to close the dimensional form of the ice-shelf equations.

\section{Scaled equations}

The zero-order system consists of the equations

$$
\begin{aligned}
& \frac{\partial \hat{\sigma}_{\xi \xi_{0}}}{\partial \hat{\xi}}=0, \\
& \frac{\partial \hat{\sigma}_{\eta \eta_{0}}}{\partial \hat{\eta}}=1, \\
& \hat{\sigma}_{\xi \xi_{0}}=\hat{\sigma}_{\eta \eta_{0}}
\end{aligned}
$$

with boundary conditions 
at $\hat{n}=0$ :

$$
\hat{\sigma}_{n n_{0}}=0
$$

at $\hat{n}=-\underline{\hat{h}}_{0}$ :

$$
\begin{gathered}
\hat{\sigma}_{\xi \xi}=-\hat{\underline{h}}_{0}, \\
\hat{\sigma}_{\eta \eta_{0}}=-\hat{\underline{h}}_{0}
\end{gathered}
$$

at $\hat{\xi}=\hat{L}$ :

$$
\int_{-\hat{h}_{0}}^{0} \hat{\sigma}_{\xi \xi_{0}} d \hat{n}=-\frac{1}{2} \hat{h}_{0}^{2} .
$$

The solution to this zero-order system is

$$
\hat{\sigma}_{\xi \xi_{0}}=\hat{\sigma}_{n \eta_{0}}=\hat{n} \text {. }
$$

The first-order system is given by the equations

$$
\begin{aligned}
& \frac{\partial \hat{\sigma}_{\xi \xi_{1}}}{\partial \hat{\xi}}+\frac{\partial \hat{o}_{\xi \eta_{3}}}{\partial \hat{\eta}}=0, \\
& \frac{\partial \hat{\sigma}_{n \eta_{1}}}{\partial \hat{n}}=0, \\
& \hat{\sigma}_{\xi \xi_{1}}^{\prime}=\frac{1}{2}\left(\hat{\sigma}_{\xi \xi_{1}}-\hat{\sigma}_{\eta \eta_{1}}\right), \\
& \frac{\partial \hat{u}_{0}}{\partial \hat{\xi}}=\hat{A} \hat{\sigma}_{\xi}^{\prime} \xi_{1}^{3}, \\
& \frac{\partial \hat{u}_{0}}{\partial \hat{n}}=0
\end{aligned}
$$

with boundary conditions

at $\hat{n}=0$ :

$$
\begin{gathered}
\hat{\sigma}_{\xi \eta_{3}}=0, \\
\hat{\sigma}_{\eta \eta_{1}}+\hat{h}_{1}^{\prime}=0,
\end{gathered}
$$

at $\hat{n}=-\hat{h}_{0}$

$$
\begin{gathered}
-\hat{\sigma}_{\xi \xi_{1}} \frac{\partial \hat{\underline{h}}_{0}}{\partial \hat{\xi}}-\hat{\sigma}_{\xi \eta_{3}}=\hat{\underline{h}}_{0} \frac{\partial \hat{\underline{h}}_{0}}{\partial \hat{\xi}}, \\
\hat{\sigma}_{\eta \eta_{1}}=-\hat{\underline{h}}_{0},
\end{gathered}
$$

at $\hat{\xi}=\hat{L}$ :

$$
\int_{-\underline{\underline{h}}_{0}}^{0} \hat{\sigma}_{\xi \xi_{1}} d \hat{n}=-\frac{1}{2} \hat{h}_{0}^{2} .
$$

From Equations (B8.2) and (B11.2),

$$
\hat{o}_{\eta \eta_{1}}=-\underline{\hat{h}}_{1}^{\prime}
$$

and, from Equation (B12.2),

$$
\hat{\underline{h}}_{1}^{\prime}=\hat{\underline{h}}_{0} \text {. }
$$

Equations (B8.2), (B9), (B10.1), and (B10.2) show that $\hat{\sigma}_{\xi \xi}$ is independent of $\hat{n}$. Integrating Equation (B8.1) over $\hat{n}$ from $\hat{n}=-\underline{\hat{h}}_{0}$ to $\hat{n}=0$ and applying boundary conditions (B11.1) and (B12.1), we find that

$$
\hat{\sigma}_{\xi \xi_{1}}=-\frac{1}{2} \hat{h}_{1}^{\prime}
$$

so that the deviatoric stress (Equation (9)) is

$$
\hat{\sigma}_{\xi \xi_{1}}^{\prime}=1 / 4 \hat{h}_{1}^{\prime}
$$

The velocity is obtained by integration of Equation (10.1)

$$
\hat{u}_{0}=\hat{u}^{*}+\frac{\hat{A}}{64} \int_{\hat{\xi}^{*}}^{\hat{\xi}} \hat{\underline{h}}_{1}^{\prime 3 \mathrm{~d}} \hat{\xi} .
$$

The shear stress, finally, follows from Equations (8.1) and (11.1)

$$
\hat{\sigma}_{\xi \eta_{3}}=\frac{1}{2} \hat{\eta} \frac{\partial \hat{h}_{1}^{\prime}}{\partial \hat{\xi}} .
$$

The complete solution to order $\omega^{2}$ is thus

$$
\begin{gathered}
\hat{\underline{h}}^{\prime}=\omega \underline{\hat{h}}+O\left(\omega^{2}\right), \\
\hat{\sigma}_{\xi \xi}=\hat{\eta}-\frac{1}{2} \hat{h}^{\prime}+O\left(\omega^{2}\right), \\
\hat{\sigma}_{\eta \eta}=\hat{\eta}-\hat{h}^{\prime}+O\left(\omega^{2}\right), \\
\hat{\sigma}_{\xi \eta}=\frac{1}{2} \omega^{2} \hat{\eta} \frac{\partial \hat{\underline{h}}^{\prime}}{\partial \hat{\xi}}+O\left(\omega^{4}\right), \\
\hat{\sigma}_{\xi \xi}^{\prime}=1 / 4 \underline{\hat{h}}^{\prime}+O\left(\omega^{2}\right), \\
\hat{u}=\hat{u}^{*}+\frac{\hat{A}}{64} \omega^{-3} \int_{\hat{\xi}^{*}}^{\hat{h}^{\prime}} \hat{h}^{\prime 3} \mathrm{~d} \hat{\xi}+O(\omega) .
\end{gathered}
$$

In the original $x, y$ coordinate system, the dimensional form of the ice-shelf equations is then, to order $\omega^{2}$,

$$
\frac{\partial H}{\partial t}+\frac{\partial}{\partial x}(H u)=a-b
$$

$$
\sigma_{x x}=-\rho_{\mathrm{i}} g\left[\frac{1}{2} \frac{\Delta \rho}{\rho_{\mathrm{w}}} H-y\right],
$$

$$
\sigma_{y y}=-\rho_{\mathrm{i}} \mathrm{g}\left(\frac{\Delta \rho}{\rho_{\mathrm{w}}} H-y\right)
$$

$$
\sigma_{x y}=\frac{1}{2} \rho_{\mathrm{i}} g y \frac{\partial h^{\prime}}{\partial x},
$$




$$
\begin{gathered}
\sigma_{x x}^{\prime}=\frac{1}{4} \rho_{\mathrm{i}} g \frac{\Delta \rho}{\rho_{\mathrm{w}}} H, \\
u=u^{*}+A\left[\frac{1}{4} \rho_{\mathrm{i}} g \frac{\Delta \rho}{\rho_{\mathrm{w}}}\right]^{3} \int_{x^{*}}^{x} H^{3} \mathrm{~d} x
\end{gathered}
$$

with, at $x=x^{*}$, boundary condition (12) on mass-flux continuity. Aside from environmental factors, the dynamical state of the ice shelf is controlled by the dominance of stretching over shearing assured by $\omega^{2} \ll \Delta \rho / \rho_{w}$, by the position of the grounding line, the discharge rate from the inland ice at the grounding line, and of course by the calving physics at the ice-shelf front.

MS. received 28 April 1986 and in revised form 24 September 1986 